\title{
A Study on Co-creation based Knowledge Storage Design
}

\author{
Hyung Rim Choi ${ }^{1}$, Min Je Cho ${ }^{2}$, Soon-Goo Hong ${ }^{3}$, Doo-hwan Kim ${ }^{4}$ \\ and Hyun Jong $\mathrm{Kim}^{5 *}$ \\ 1,2,3,4, 5 Department of Management Information Systems, Dong-A University, \\ Republic of Korea \\ 1hrchoi@dau.ac.kr, ${ }^{2}$ mjcho@dau.ac.kr, ${ }^{3}$ shong@dau.ac.kr, \\ ${ }^{4}$ kdhblack@donga.ac.kr, ${ }^{5}$ hatdol@gmail.com
}

\begin{abstract}
Co-creation models have been proposed as a new way to solve social problems with the cooperation of various stakeholders to overcome limitations of administrative agencyled policy development and implementations. Case studies on the co-creation-modelbased policy development are necessary because co-creation models require new procedures different from the existing policy development. The aim of this study is to design a knowledge storage that can access and utilize previous cases of co-creation models in developing and implementing policies to solve social problems and promote regional innovations. For this purpose, this study reviews the basic requirements of the knowledge storage and designs a logical and physical model of the co-creation-based knowledge storage. This study contributes to academic researches that can lead to subsequent studies on co-creation models and platforms.
\end{abstract} Cases

Keywords: Co-creation models, Knowledge Storage, Regional Innovations, Policy

\section{Introduction}

Administrative agencies have developed and implemented policies to solve diverse social problems and promote regional innovations. However, there were many cases of administrative agency-led policies that often failed to reflect the needs of the residents, and it was difficult to find a mutually agreed solution due to the complex relationship of stakeholders. Recently, there have been more and more cases of resident-oriented policies being promoted to overcome the problems of administrative agency-led policies.

The resident-oriented policies are being used to meet the real needs of residents, and it is prompted with the participatory approaches used in the process of policy development and implementation by including ideas of residents. 'Chunmansangsang Oasis (Thousand Imagination Oasis)' of Seoul and 'Design Thinking' of Rochester are representative cases of regional innovation policy [1].

Stakeholders' involvements, as seen in the resident-oriented policies, are well illustrated in the concept of co-creation. The concept of creating new value through the participation of diverse stakeholders has begun in the management field, and now it is increasingly used in the administrative field as well. In the administrative field, cocreation models have been proposed to support the methods and procedures of co-creation for solving social problems and promoting innovation. If the methods and procedures of the co-creation model suggested in this study are followed, administrations can carry out the process from problem finding to policy implementation [2]. The co-creation model differs from the existing policy development in terms of the participatory approaches of

Received (January 16, 2017), Review Result (June 15, 2017), Accepted (September 26, 2017)

* Corresponding Author 
diverse stakeholders. Since it is still an unfamiliar method, it is necessary to refer to previous similar cases or successful cases to utilize the model. There was a database and knowledge management system to refer to the previous policy cases. However, the system has limitations that it does not effectively manage and provide users the needed information and knowledge because of the information scattering. Therefore, it is necessary to develop a knowledge storage that effectively manages previous policy cases and provides knowledge of them. The aim of this study is to develop a co-creation-modelbased knowledge storage.

This knowledge storage systematically stores previous cases of co-creation-based policy development and implementations. When a user develops or implements a cocreation-model-based policy, he/she can effectively find the best practices or similar cases from the knowledge storage. With regards to the design of the knowledge storage, this study defines a concept and requirements of the knowledge storage to effectively utilize a co-creation model, and investigate the value of the knowledge storage design for practical use.

\section{Theoretical Background}

\subsection{Co-Creation Model}

The concept of co-creation model that was suggested in the administrative field refers to a mutual creation of new value set by enterprises and consumers and shared benefits derived from the mutual works [3]. Through co-creation, enterprises gain new ideas from consumers for products and marketing, and consumers can actively participate in corporate activities to help create value for the company. For instance, companies such as 'Quirky' actively utilize the concept of co-creation to get ideas from consumers for new products and reflect their opinions to develop, produce, as well as, sell new products, and distribute their benefits to the people who provide opinions to the company [4]. Cocreation process involves idea generation, idea selection, development of goods or services, and commercialization. This co-creation model can be applied to solve social problems. When specifying a characteristic or searching a solution for a specific social problem such as job mismatching, participation of residents or experts could produce more effective and practical resolution. A co-creation model can be used as a way to get ideas from the outside [5].

\subsection{Knowledge Storage}

In the field of information technology and data analysis, knowledge means information that is more systematized and conceptualized, and makes the use of information easier. What distinguishes knowledge from simple information is its purpose and intended use. Knowledge allows the independent information to be structured in line with the purpose and its intended use and to be valuable information or to be used efficiently. Knowledge storage is defined as a tool for creating and sharing value by storing and reusing the existing knowledge [6]. In relation to the definition of knowledge, Knowledge Storage is a platform to systemize, structure, and store information that can be provided to users efficiently and effectively.

There are similar concepts to Knowledge Storage that exist, knowledge management systems and expert systems. A knowledge management system is an information system that improves individual and organizational performance by organizing and sharing the individual knowledge accumulated by the organization members [7]. Expert systems provide knowledge efficiently for the purpose of solving the problem, such as using the knowledge gained from the expert through the inference function [8]. As such, the use of knowledge is to structure simple data and information and utilize it efficiently based on its intended use. Knowledge structuring refers to the defining of the complex relationships of 
information based on certain rules in order to store and generate knowledge. It enables us to find the relationship and meaning of information and get accurate knowledge.

\section{Co-creation based Knowledge Storage Design}

\subsection{Characteristics of Policy Cases}

The policy cases that will be stored in the proposed Knowledge Storage have the following characteristics;

i) The cases have limited data on policy planning and implementation, and it is difficult to comprehend the data because it is separately managed by legislative and administrative departments.

ii) It is difficult to interpret the contents of the cases and to integrate cases because those were formed in documents mainly.

iii) In cases such as papers and reports, the form, content and volume are different and do not have a standardized form.

iv) Articles and posters briefly presented in terms of implementation background, progress, and results of the project, and the contents are insufficient to interpret the cases accurately.

v) There are many cases where basic information such as name, period, and location of the institution are omitted or details are not described.

vi) Previous cases are often inconsistent with the co-creation model.

With these characteristics of policy cases, it is necessary to integrate and structure policy cases to utilize policy cases as knowledge. Considering the characteristics, the cocreation-model-based Knowledge Storage needs to be divided into three information fields - basic information, classification information, and step-by-step information.

First, the basic information is a general information on the policy cases. It is composed of the name of the policy case, the host organization, the planning and implementation period, and stakeholders. Second, classification information includes information to classify the policy cases used in searching and inferring. Classification information has information such as the type of cases, problem resolutions, and the presence or absence of conflict. Third, the step-by-step information provides detailed processes and information on the progress of the case, and detailed information on the progress of the co-creation model.

\subsection{Requirements Analysis}

To analyze the requirements for the development of the co-creation-based Knowledge Storage, this study reviews previous researches on policy cases, knowledge repositories, and co-creation models. Also interviews with experts of information systems, co-creation models, and policies, and administrators were conducted to derive to the necessary requirements.

i) Knowledge about co-creation-based policy development and implementation is needed.

ii) Providing useful knowledge: Information includes cases of regional innovation that can be provided as references for policy making and administrative tasks of regional innovation, as well as, basic information and step-by-step information that are needed in addition to document files.

iii) Providing accurate cases: the user should be able to retrieve accurate cases from various cases.

iv) Providing step-by-step best practices: the best practices of step-by-step methods and procedures that can be consulted when establishing and implementing regional innovation policies are needed, according to regional innovation model and platform, 
v) Renewing knowledge and sharing experiences: Continuous storage of new cases and sharing of opinions and empirical knowledge on cases between users are required.

The functional requirements of the Knowledge Storage are as follows;

i) Input function: It is necessary to have a convenient category and interface for structuring and inputting various cases.

ii) Search function: It is necessary to have a fast and accurate case search function with keywords and detailed search function.

iii) Management function: Data management function such as modification and deletion of stored cases is required.

Through the analysis of the requirements, the co-creation-based knowledge storage differs from the existing knowledge storage. The intrinsic purpose of accumulating and reusing of knowledge is the same, but the proposed co-creation knowledge storage differs in terms of storing and utilizing knowledge. The differences are shown in Table 1 below.

\section{Table 1. Differences between the Existing Knowledge Storage and Co- Creation Based Knowledge Storage}

\begin{tabular}{|c|c|c|}
\hline Division & Existing Knowledge Storage & $\begin{array}{c}\text { Co-creation based Knowledge } \\
\text { Storage }\end{array}$ \\
\hline Purpose & $\begin{array}{l}\text { Knowledge creation, knowledge sharing, } \\
\text { knowledge reuse }\end{array}$ & $\begin{array}{l}\text { Knowledge accumulation, knowledge } \\
\text { search, knowledge reuse }\end{array}$ \\
\hline $\begin{array}{l}\text { Administrative } \\
\text { agency }\end{array}$ & $\begin{array}{l}\text { - Purpose of integration of distributed } \\
\text { work or policy knowledge, knowledge } \\
\text { sharing, administrative service } \\
\text { improvement } \\
\text { - It is mainly used to store and share } \\
\text { business documents and materials rather } \\
\text { than knowledge of administrative or } \\
\text { policy process. }\end{array}$ & $\begin{array}{l}\text {-Co-creation based social problem } \\
\text { solving, the purpose of knowledge } \\
\text { scaling, reuse of policy development } \\
\text { - Co-creation of policy cases and } \\
\text { accumulation of knowledge in stages } \\
\text { - Provide knowledge on the methods and } \\
\text { procedures of policy development and } \\
\text { implementation process }\end{array}$ \\
\hline Save or Manage & $\begin{array}{l}\text { - Structuring systematic database through } \\
\text { metadata, knowledge map, classification } \\
\text { system } \\
-\quad \text { Knowledge type, importance, } \\
\text { synonyms, index }\end{array}$ & $\begin{array}{l}\text { - In addition to basic information of past } \\
\text { policy cases, co-creation model type, } \\
\text { step-by-step classification system }\end{array}$ \\
\hline Reuse (search) & $\begin{array}{l}\text { - Knowledge search by search priority } \\
\text { according to classification system }\end{array}$ & $\begin{array}{l}\text { - Main index of policy basic information, } \\
\text { co-creation type of classification } \\
\text { information, retrieving case information } \\
\text { by stages } \\
\text { - Full information on policy cases, } \\
\text { information utilization at each stage }\end{array}$ \\
\hline
\end{tabular}

In addition, the key functions required to the Knowledge Storage are the input, retrieval, output, and management functions that are shown in Table 2 below. 
Table 2. Key Functions of Knowledge Storage

\begin{tabular}{|c|l|l|}
\hline \multirow{5}{*}{ Key function } & \multicolumn{1}{|c|}{ Detail function } & \multicolumn{1}{c|}{ Description } \\
\hline \multirow{2}{*}{ Case Input } & Basic information input & $\begin{array}{l}\text { Input basic information such as case name, } \\
\text { period, host institution, stakeholders, project } \\
\text { outline, keywords, etc. }\end{array}$ \\
\cline { 2 - 3 } & Classification information input & $\begin{array}{l}\text { Input type of case, solution method, and degree } \\
\text { of conflict. }\end{array}$ \\
\cline { 2 - 3 } Case Search & Step-by-step information input & Input case details by step 1 - 8. \\
\hline \multirow{2}{*}{\begin{tabular}{c} 
Case Output \\
\cline { 2 - 3 } Case
\end{tabular}} & General/Advanced search & Search cases with keywords and search items. \\
\cline { 2 - 3 } Management & Step-by-step information output & Output information of whole cases. \\
\hline \multirow{2}{*}{$\begin{array}{c}\text { Platform } \\
\text { interlocking }\end{array}$} & Interlocking with co-creation platform & $\begin{array}{l}\text { Provide similar or representative case requested } \\
\text { from co-creation platform, and then input and } \\
\text { save contents derived from the platform. }\end{array}$ \\
\hline
\end{tabular}

\subsection{Architectural Design}

The knowledge storage consists of two parts - knowledge registry and knowledge repository - to effectively implement key functions of the knowledge storage. Cases are saved in the knowledge repository and managed by the knowledge registry.
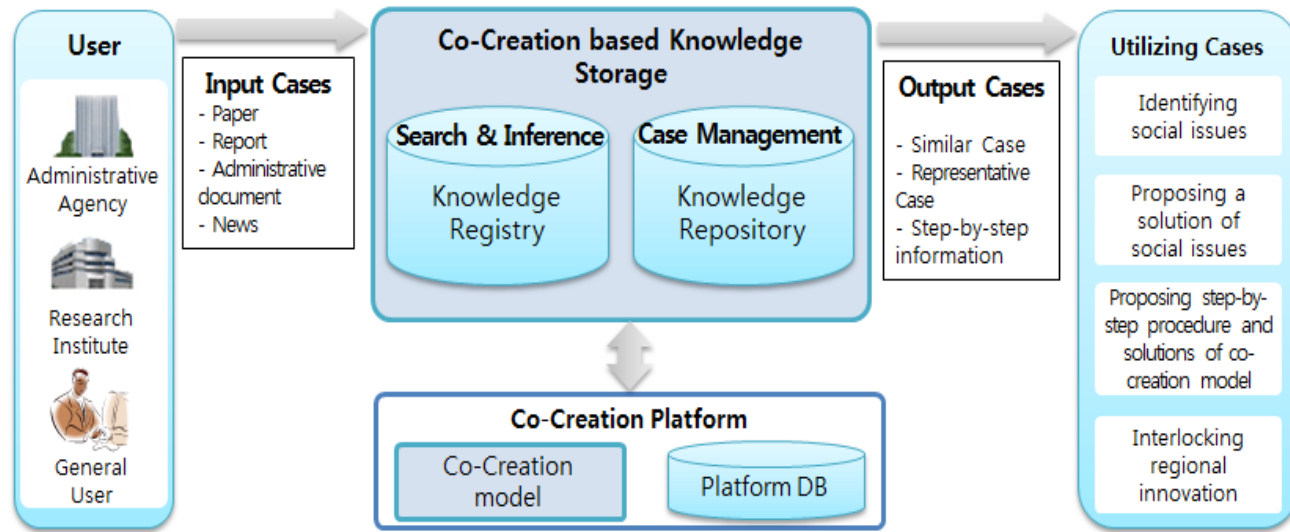

Figure 1. Block Diagram of Knowledge Storages

The knowledge registry stores information related to knowledge storage operations and is responsible for the functions of input, output, retrieval, and inference of cases. The knowledge repository is a space where co-creation cases are structured and stored. The regional innovation platform is an information system for policy development and implementation by using the co-creation model, and it provides the best practices that can be referenced step-by-step in the co-creation model in cooperation with the knowledge storage.

\section{4. Logical Design}

Figure 2 summarizes the process of the Knowledge Storage that was defined based on the main functions of the Knowledge Storage derived from the requirements analysis. 


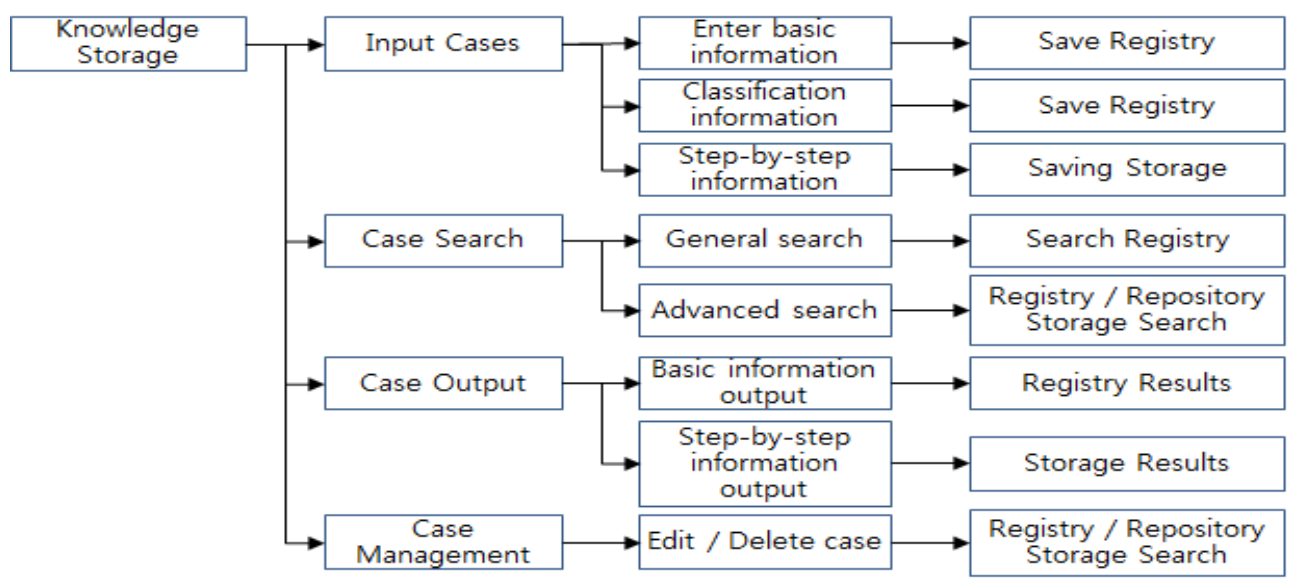

Figure 2. Knowledge Storage Process

Figure 3 shows the relationship between the entities which were derived from the key functions and process of the knowledge storage.

A logical design defines an entity and its attribute as a specific information item managed by an entity. Entities and attributes defined in the logical design are converted into table for entities and columns for attributes. The proposed Knowledge Storage consists of 12 entities, 5 entities for knowledge registry, and 7 entities for knowledge repository.

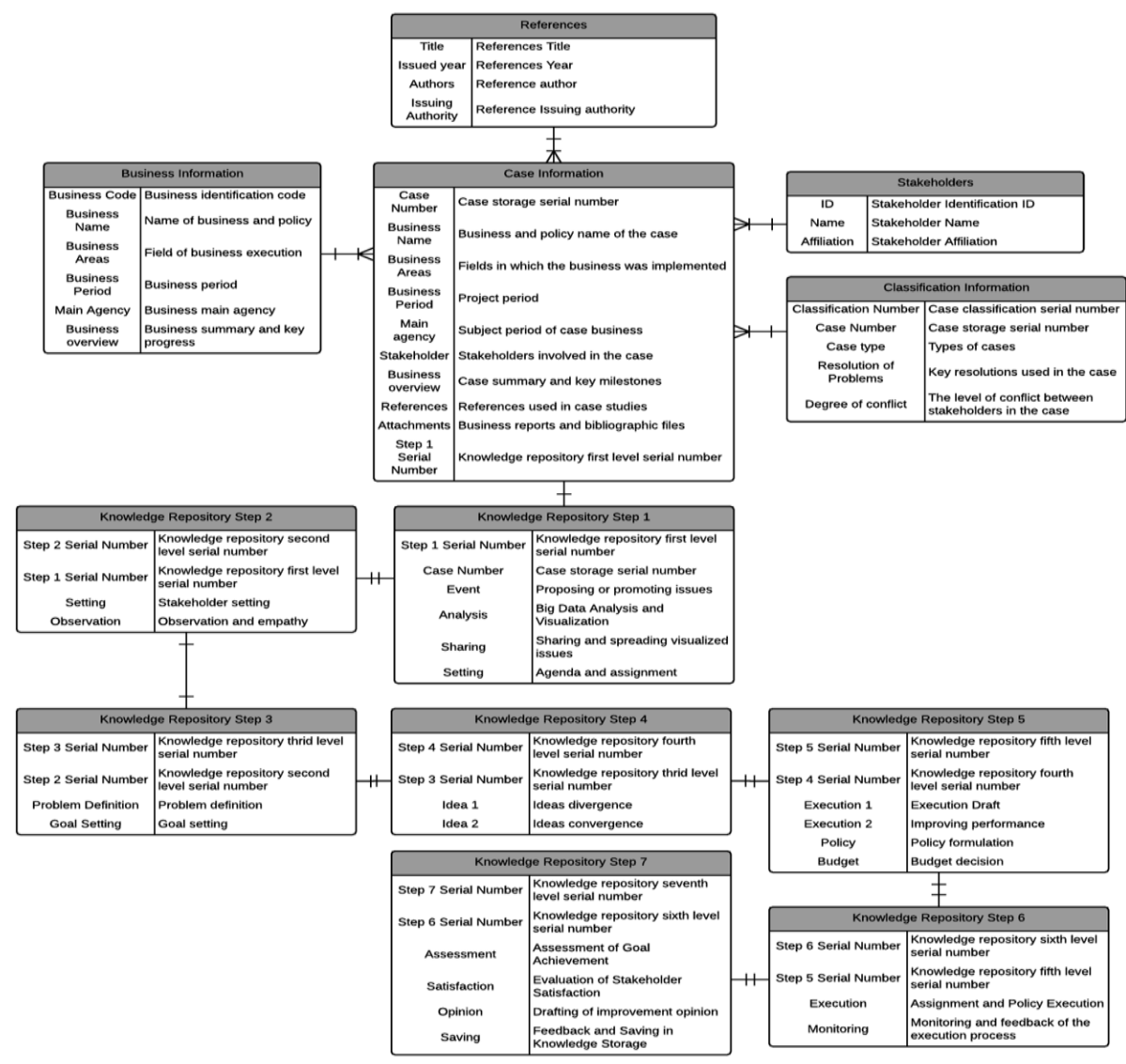

Figure 3. Logical Design of Knowledge Storage 
Each field and attribute of Knowledge Storage contains basic information, classification information, and step-by-step information as Table 3, Table 4, Table 5, Table 6, Table 7, and Table 8 .

Table 3. Basic Information

\begin{tabular}{|c|c|}
\hline Field & Attributes \\
\hline $\begin{array}{l}\text { Case Number } \\
\text { (PK) }\end{array}$ & Case storage serial number \\
\hline Business Name & $\begin{array}{l}\text { Business and policy name of the } \\
\text { case }\end{array}$ \\
\hline Business Areas & $\begin{array}{l}\text { Fields in which the business was } \\
\text { implemented }\end{array}$ \\
\hline Business Period & Project period \\
\hline Main agency & Subject period of case business \\
\hline Stakeholder & $\begin{array}{l}\text { Stakeholders involved in the } \\
\text { case }\end{array}$ \\
\hline $\begin{array}{l}\text { Business } \\
\text { Overview }\end{array}$ & $\begin{array}{l}\text { Case summary and key } \\
\text { milestones }\end{array}$ \\
\hline References & References used in case studies \\
\hline Attachments & $\begin{array}{l}\text { Business reports and } \\
\text { bibliographic files }\end{array}$ \\
\hline $\begin{array}{l}\text { Step } 1 \text { Serial } \\
\text { Number }\end{array}$ & $\begin{array}{l}\text { Knowledge tributary first level } \\
\text { serial number }\end{array}$ \\
\hline
\end{tabular}

Table 5. Stakeholders

\begin{tabular}{|c|l|}
\hline Field & \multicolumn{1}{|c|}{ Attributes } \\
\hline ID & Stakeholder Identification \\
\hline Name & Stakeholder Name \\
\hline Affiliation & Stakeholder Affiliation \\
\hline
\end{tabular}

Table 4. Classification Information

\begin{tabular}{|c|c|}
\hline Field & Attributes \\
\hline $\begin{array}{l}\text { Classification } \\
\text { Number } \\
\text { (PK) }\end{array}$ & $\begin{array}{l}\text { Case classification serial } \\
\text { number }\end{array}$ \\
\hline $\begin{array}{l}\text { Case } \\
\text { Number }\end{array}$ & Case storage serial number \\
\hline $\begin{array}{l}\text { Business } \\
\text { Name }\end{array}$ & $\begin{array}{l}\text { Business and policy name of the } \\
\text { case }\end{array}$ \\
\hline Case Type & $\begin{array}{l}\text { Types of cases ( } 4 \text { types: policy } \\
\text { development or policy } \\
\text { enforcement, conflict high or } \\
\text { low) }\end{array}$ \\
\hline $\begin{array}{l}\text { Resolution of } \\
\text { Problems }\end{array}$ & Key resolutions used in the case \\
\hline $\begin{array}{l}\text { Degree of } \\
\text { Conflict }\end{array}$ & $\begin{array}{l}\text { The level of conflict between } \\
\text { stakeholders in the case }\end{array}$ \\
\hline
\end{tabular}

Table 6. References

\begin{tabular}{|c|l|}
\hline Field & \multicolumn{1}{|c|}{ Attributes } \\
\hline Title & References Title \\
\hline Issued Year & References Year \\
\hline Authors & Reference Author \\
\hline $\begin{array}{c}\text { Issuing } \\
\text { Authority }\end{array}$ & Reference Issuing Authority \\
\hline
\end{tabular}

Table 7. Business Information

\begin{tabular}{|c|l|}
\hline \multicolumn{1}{|c|}{ Field } & \multicolumn{1}{c|}{ Attributes } \\
\hline Business Code & Business Identification Code \\
\hline Business Name & Name of Business and Policy \\
\hline Business Areas & Field of Business Execution \\
\hline Business Period & Business Period \\
\hline Main Agency & Business Main Agency \\
\hline Business overview & Business Summary and Key Progress \\
\hline
\end{tabular}


Table 8. Step-by-Step Information of Knowledge Storage

\begin{tabular}{|c|c|}
\hline Key function & Detail function \\
\hline \multirow{4}{*}{$\begin{array}{c}\text { Stepl } 1 \\
\text { Discovery of Tasks }\end{array}$} & 1-1 Proposing or promoting issues \\
\hline & 1-2 Big data Analysis and visualization \\
\hline & 1-3 Sharing and spreading visualized issues \\
\hline & 1-4 Agenda and assignment \\
\hline \multirow{2}{*}{$\begin{array}{c}\text { Step } 2 \\
\text { Empathy and Understand Issues }\end{array}$} & 2-1 Stakeholder setting \\
\hline & 2-2 Observation and empathy \\
\hline \multirow{3}{*}{$\begin{array}{c}\text { Step } 3 \\
\text { Problem Definition }\end{array}$} & 3-1 Searching materials \\
\hline & 3-2 Problem definition \\
\hline & 3-3 Goal setting \\
\hline \multirow{2}{*}{$\begin{array}{c}\text { Step } 4 \\
\text { Deriving Ideas }\end{array}$} & 4-1 Idea divergence \\
\hline & 4-2 Idea convergence \\
\hline \multirow{3}{*}{$\begin{array}{c}\text { Step } 5 \\
\text { Reinventing Ideas }\end{array}$} & 5-1 Execution draft \\
\hline & 5-2 Improving performance \\
\hline & 5-3 Policy formulation and budget decision \\
\hline \multirow{2}{*}{$\begin{array}{c}\text { Step } 6 \\
\text { Execution }\end{array}$} & 6-1 Assignment and policy execution \\
\hline & 6-2 Monitoring and feedback of the execution process \\
\hline \multirow{4}{*}{$\begin{array}{c}\text { Step } 7 \\
\text { Assessment and Feedback }\end{array}$} & 7-1 Assessment of goal achievement \\
\hline & 7-2 Evaluation of stakeholder satisfaction \\
\hline & 7-3 Drafting of improvement opinion \\
\hline & 7-4 Feedback and saving in knowledge storage \\
\hline
\end{tabular}

\subsection{Physical Design}

Based on the entities and attributes derived from the logical design, it was physically designed as shown in Figure 4, and the data model was improved efficiently through the normalization and semi-normalization process.

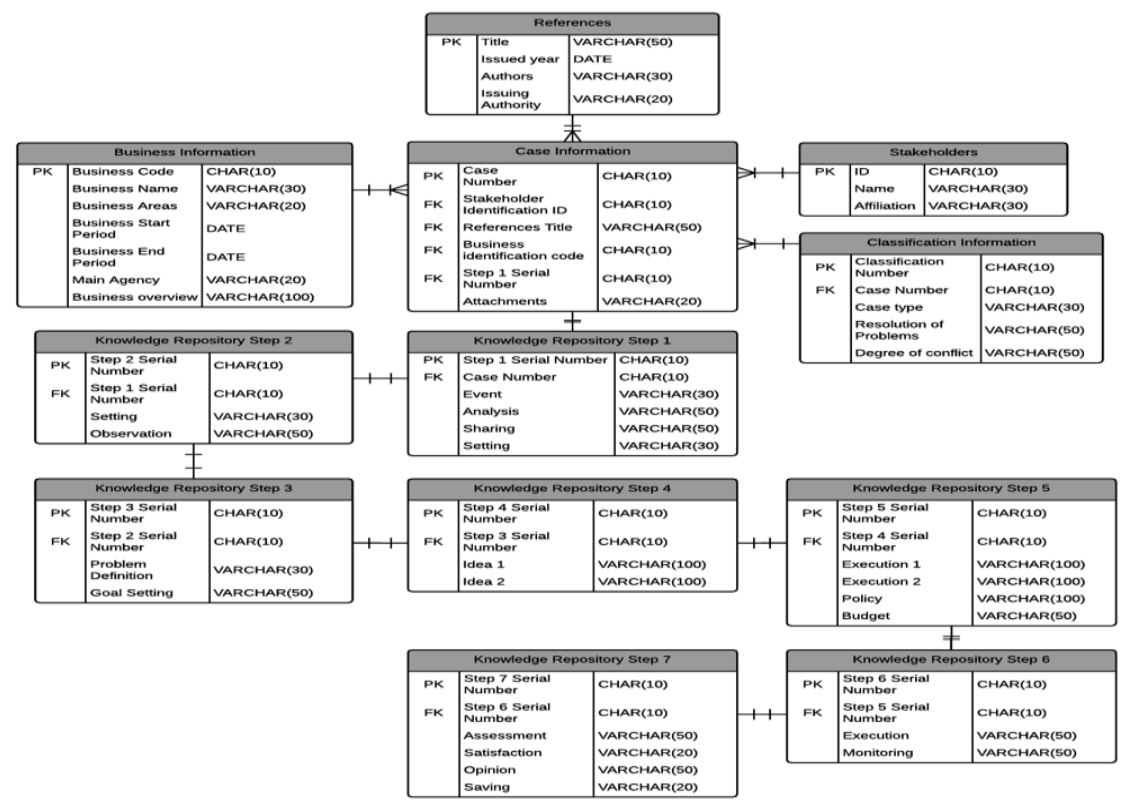

Figure 4. Physical Design of Knowledge Storage 
Entities of the logical design are defined as physical tables and are defined as the data type, length, and area values in terms of the DBMS (Database Management System) perspective. This study made Knowledge Storage by using MySQL.

\section{Conclusion}

The aim of this study was to design a knowledge storage to provide and manage previous policy cases that can be referenced in implementing co-creation models effectively. For this purpose, this study defined key function of Knowledge Storage through requirement analysis and conducted a co-creation-based knowledge storage architecture, process, and logical and physical designs.

The existing knowledge management system, which has been used in the past, mainly shares data such as administrative documents and makes it difficult to provide knowledge effectively. In contrast, the Co-creation-based Knowledge Storage proposed in this study has the advantage of effectively providing the detailed contents of the process and the knowledge for each step.

This study contributes to providing a base data of co-creation model and platform by developing a Knowledge Storage to support a platform for implementing the co-creation model, as well as, induce follow-up researches. However, in a practical sense, this study has limitations in the realization of the actual Knowledge Storage and verification of its validity. In future researches, it is necessary to realize the Knowledge Storage and to investigate the application performance of the Knowledge Storage.

\section{Acknowledgments}

This work was supported by the Ministry of Education of the Republic of Korea and the National Research Foundation of Korea(NRF-2015S1A3A2046781)

\section{References}

[1] J. S. Park, S. G. Hong and N. R Kim, "A Development Plan for Co-creation-based Smart City through the Trend Analysis of Internet of Things", Journal of the Korea Industrial Information Systems Research, vol. 21 , no. 4, (2016), pp. 67-78.

[2] S. G. Hong, H. J. Kim and N. R. Kim, "Development of a Co-creation Model for the Social Problem Resolution”, INFORMATION-An International Interdisciplinary Journal, vol. 19, no. 8(B), (2016), pp. 3395-3400.

[3] C. K. Prahalad and V. Ramaswamy, "The Future of Competition: Co-Creating Unique Value with Customers", Harvard Business School Press, Boston, (2004).

[4] Quirky, https://www.quirky.com/

[5] S. G. Hong, S. E. Han and H. M. Lee, "A Study on the Co-creation for Problem-solving of Regional Community", Journal of Korean Association for Regional Information Society, vol. 17, no. 1, (2014), pp. $1-24$.

[6] S. J. Choi and S. J. Shin, "Improving Service Quality by Using Organizational Memory in Electronic Knowledge Repositories : Focusing on Shared Service Value and Knowledge Reuse", Korea Journal of Business Administration, vol. 25, no. 9, (2015), pp. 3511-3531.

[7] H. G. Gong, "Empirical Study on the Effect of Knowledge Sharing on Knowledge Management System", Ph.D thesis, Chonnam National University, (2004).

[8] P. Drucker, "The Information Executives Truly Need", Harvard Business Review, vol. 73, no. 1, (1995), pp. 54-63. 


\section{Authors}

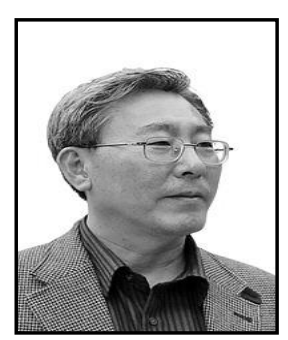

Hyung Rim Choi, he is a Professor Hyung Rim Choi is currently a Professor of MIS at School of Business, Dong-A University. He received his Ph.D. in Management Science from Korea Advanced Institute of Science and Technology (KAIST). His current research interests include IoT, Supply Chain Management, Logistics and Cocreation.

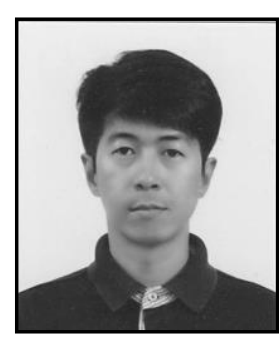

Min Je Cho, he is a Professor Min Je Cho is currently a Professor of MIS at School of Business, Dong-A University. He received his $\mathrm{Ph} . \mathrm{D}$. in MIS from Dong-A University. His current research interests include IoT, Supply Chain Management, Co-creation and Business Intelligence.

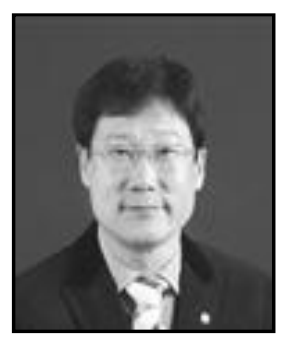

Soon-Goo Hong, he is a Professor in the department of Management Information Systems at Dong-A University, Korea. $\mathrm{He}$ holds a Ph.D. in management from the University of Nebraska-Lincoln. $\mathrm{He}$ is currently working for regional innovation by utilizing IT and Co-creation. He serves as a chair of the IT and Co-creation based Regional Innovation Research Group.

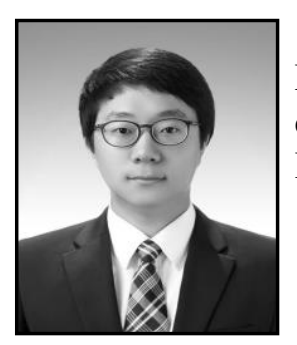

Doo-hwan Kim, he is Doctor Course Doo-hwan Kim received the Master of Business Administration from Dong-A University. His current research interests include IoT, Supply Chain Management, Big data and Co-creation.

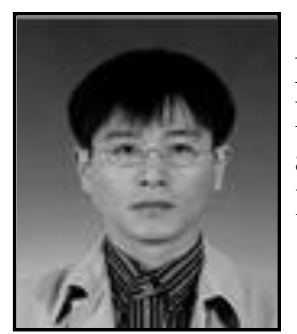

Hyun Jong Kim, he is a Ph.D. candidate at the Department of Management Information Systems at Dong-A University, Korea. $\mathrm{He}$ is currently working for regional innovation by utilizing IT and Co-creation. His research interests are including the areas of Knowledge storage, platform, and Big data. 